\title{
The effect of COPD severity and study duration on exacerbation outcome in randomized controlled trials
}

This article was published in the following Dove Press journal:

International Journal of COPD

15 May 2017

Number of times this article has been viewed

\author{
Göran Eriksson' \\ Peter M Calverley ${ }^{2}$ \\ Christine R Jenkins ${ }^{3,4}$ \\ Antonio R Anzueto ${ }^{5}$ \\ Barry J Make \\ Magnus Lindberg ${ }^{7}$ \\ Malin Fagerås ${ }^{7}$ \\ Dirkje S Postma ${ }^{8}$
}

'Department of Respiratory Medicine and Allergology, University Hospital,

Lund, Sweden; ${ }^{2}$ Pulmonary and

Rehabilitation Research Group,

University Hospital Aintree,

Liverpool, UK; ${ }^{3}$ Concord Clinical

School, University of Sydney, ${ }^{4}$ The

George Institute for Global Health,

Sydney, Australia; ${ }^{5}$ Department of

Pulmonary Medicine and Critical

Care, University of Texas Health

Sciences Center and South Texas

Veterans' Health Care System, San

Antonio, Texas, ' ${ }^{6}$ Division of Pulmonary Sciences and Critical Care Medicine,

National Jewish Health, University of Colorado, Denver, Colorado, USA;

${ }^{7}$ AstraZeneca R\&D, Mölndal, Sweden; ${ }^{8}$ Department of Pulmonary Medicine and Tuberculosis, University Medical Center Groningen, GRIAC Research Institute, University of Groningen, Groningen, the Netherlands
Background: When discontinuation in COPD randomized controlled trials (RCTs) is unevenly distributed between treatments (differential dropout), the capacity to demonstrate treatment effects may be reduced. We investigated the impact of the time of differential dropout on exacerbation outcomes in RCTs, in relation to study duration and COPD severity.

Methods: A post hoc analysis of 2,345 patients from three RCTs of 6- and 12-month duration was performed to compare budesonide/formoterol and formoterol in moderate, severe, and very severe COPD. Outcomes were exacerbation rate, time-to-first exacerbation, or discontinuation; patients were stratified by disease severity. Outcomes were studied by censoring data monthly from 1 to 12 months.

Results: In patients treated with budesonide/formoterol, annualized exacerbation rates (AERs) were comparable for each study duration (rate ratio $[R R]=0.6$ ). With formoterol, the AER decreased with study duration ( $R R=1.20$ at 1 month to $R R=0.86$ at 12 months). There was a treatment-related difference in exacerbation rates of $45 \%-48 \%$ for shorter study durations ( $\leq 4$ months) and $27 \%$ for 12 -month duration. This treatment-related difference in exacerbation rates was comparable for the three disease severities in studies $\leq 4$ months (range: $39 \%-51 \%$ ), but this difference decreased with longer study durations, especially in more severe groups ( $22 \%$ and $29 \%$ at 12 months). There were fewer discontinuations with budesonide/formoterol; the treatmentrelated difference in time-to-first discontinuation decreased by study duration $(35 \%, 30 \%, 26 \%$, and $22 \%$ at 3, 6, 9, and 12 months, respectively). Numbers of differential dropouts increased with increasing disease severity, being greatest during second, third, and fourth months.

Conclusions: COPD severity and study duration impact exacerbation as an outcome in double-blind RCTs. This effect is most obvious in patients with severe/very severe COPD and in studies that are longer than 4 months. Early differential dropout particularly impacts study outcome, producing a "healthy survivor effect," which reduces estimations of treatment impact on exacerbations.

Keywords: healthy survivor effect, exacerbation outcomes, early differential dropout, RCT, disease severity

\section{Background}

In patients with COPD, double-blind, randomized controlled trials (RCTs) conducted over 6-12 months are regarded as the most rigorous way to evaluate the efficacy of treatments for symptomatic benefit and/or prevention of future risks, such as exacerbations. ${ }^{1}$ These trials often show significant treatment effects compared with placebo, but differences between active treatment arms may only be seen when data are pooled or larger studies conducted. ${ }^{2-4}$ A consistent finding in RCTs in COPD patients is a high 
rate of discontinuation, ranging from $27 \%$ to $53 \%,{ }^{5}$ especially among those with more severe disease. Furthermore, discontinuation occurs early in a trial ${ }^{6,7}$ and correlates with disease severity. ${ }^{8}$ This should not cause a major problem when interpreting RCTs, provided that discontinuation is a random phenomenon between the interventions studied. However, the power calculation for the primary variable needs to compensate for this effect, as the loss of information over time may impact the ability of the study to confidently identify or exclude a treatment effect. A particular problem arises when differential dropout between study arms occurs on top of evenly distributed random discontinuations. The net effect can lead to potential bias in favor of a weaker treatment, if the sicker people in that arm are lost during follow-up. ${ }^{9}$

In this report, we investigate the impact of both disease severity and study duration on COPD exacerbations in double-blind RCTs. A secondary objective was to better understand the impact of premature discontinuations, on exacerbation frequency and treatment effect in relation to disease severity and study duration. A large data set from three $\mathrm{RCTs}^{10-12}$ was interrogated as the basis for these analyses.

\section{Methods}

\section{Study design and patient population}

We analyzed data from three double-blind, randomized, double-dummy, parallel-group, placebo-controlled, multicenter clinical trials of 6 (NCT00206154 $4^{12}$ ) and 12 months duration (NCT00206167 $7^{10}$ and NCT00419744 ${ }^{11}$ ). The efficacy of budesonide/formoterol 320/9 $\mu \mathrm{g}$ and formoterol $9 \mu \mathrm{g}$ (two inhalations twice daily) (AstraZeneca, Mölndal, Sweden) was compared in patients with COPD. Salbutamol (albuterol) was allowed as reliever medication during screening, run-in, and throughout all studies. All studies were conducted in accordance with the Declaration of Helsinki, Good Clinical Practice guidelines, and applicable regulatory requirements; all patients gave written, informed consent. These previously published trials were conducted in 237 sites in the USA, Europe, and Mexico; ${ }^{10} 180$ sites in the USA, Central and South America, and South Africa; ${ }^{11}$ and 194 centers in the USA, Czech Republic, the Netherlands, Poland, and South Africa. ${ }^{12}$ Ethical approval was provided in all countries by local Independent Ethics Committees at the time when the studies were first conducted, and details have previously been published. ${ }^{10-12}$

The study inclusion criteria were similar: smokers or ex-smokers with a smoking history of $\geq 10$ pack-years; pre-bronchodilator forced expiratory volume in 1 second $\left(\mathrm{FEV}_{1}\right) \leq 50 \%$ predicted; pre-bronchodilator $\mathrm{FEV}_{1} /$ forced vital capacity (FVC) ratio $<70 \%$; age $\geq 40$ years; COPD with a history of $\geq 1$ COPD exacerbation requiring treatment with a course of systemic corticosteroids, antibiotics, or both 1-12 months prior to screening; and a modified Medical Research Council dyspnea score of $\geq 2$.

\section{COPD severity and study duration}

The impact of disease severity on exacerbation and dropout was assessed by stratifying patients by lung function - moderate, severe, and very severe - according to GOLD recommended criteria. ${ }^{13}$ Study duration was evaluated by censoring data after 1, 2, 3 months, etc., up to 12 months, thereby generating 12 subanalyses of increasing duration.

\section{Exacerbation as an endpoint}

Our primary outcome was the impact of study duration and disease severity on exacerbations. A COPD exacerbation was defined as a worsening of COPD symptoms requiring treatment with oral corticosteroids and/or hospitalization. Exacerbations were recorded by patients in diary cards and confirmed at a clinic visit by study investigators/coordinators.

\section{Discontinuation as an endpoint}

All discontinuations, irrespective of the reason, were summarized by treatment. Individual reasons for discontinuations were also assessed for each treatment: failure to fulfill eligibility criteria, adverse event, withdrawal of consent (voluntary discontinuation by patient), lost to follow-up, and others.

\section{Exploratory endpoints}

We investigated at which month(s) of follow-up the differential dropout peaked by conditional probability of dropout (CPDo), that is, the number of discontinuations in a month divided by the number of patients entering the defined month. A composite of exacerbation and discontinuation (ExDo) was created to evaluate whether early discontinuation could compensate for the loss of treatment effect on exacerbations over time due to early differential dropout.

\section{Statistical analyses}

Analyses were performed for the overall patient population and the COPD severity subgroups - moderate, severe, and very severe. The impact of study duration was analyzed cumulatively for $0-1,0-2,0-3$, etc., up to $0-12$ months of duration, that is, data after the defined study duration were censored. As one trial ${ }^{12}$ had shorter study duration, these data were censored at 6 months. Differences in rates were analyzed using Poisson regression with study as a factor. Time-to-first events (exacerbation, discontinuations, and ExDo) were analyzed 
using Cox-regression analysis with study as a factor. Rate ratios (RRs) and hazard ratios (HRs) with 95\% confidence intervals and $P$-values were provided. Treatment-related differences (RR and HR) were expressed as percentage reduction in exacerbations. CPDo was summarized descriptively up to 6 months. Analyses used standard statistical software (SAS v9.2; SAS Institute, Inc., Cary, NC, USA).

\section{Results}

\section{Demographics and baseline characteristics}

Overall, 2,345 COPD patients (mean age: 63 years; $63 \%$ male) were included in the analysis. Demographics and baseline characteristics for all patients, according to disease severity, are shown in Table 1. Studies included (mean) 17\% moderate, $57 \%$ severe, and 26\% very severe COPD patients

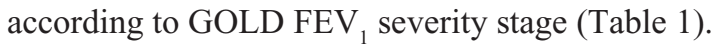

\section{Effect of study duration and disease severity on exacerbation}

\section{Exacerbations in all patients}

Exacerbation rates per treatment were higher with longer study duration and more so with formoterol ( $R R=0.86$ at 12 months) than with budesonide/formoterol $(\mathrm{RR}=0.63$ at 12 months) (Figure 1A).

Annualized exacerbation rates (AERs) per treatment In patients treated with budesonide/formoterol, the AERs for each study duration period were comparable irrespective of study duration ( $R R \approx 0.6$ exacerbation per patient and year). In the formoterol arm, the AER decreased from $\mathrm{RR}=1.20$ to $\mathrm{RR}=0.86$ (a $28 \%$ reduction) over the 12-month period (Figure 1B; Table S1).

\section{Relative treatment difference in exacerbation rate}

The differences between treatments in the exacerbation rates decreased with longer study duration. The reduction in favor of budesonide/formoterol was $45 \%-48 \%$ for shorter study durations ( $\leq 4$ months) and $27 \%$ for a study duration of 12 months (Figure 1C; Table S2).

\section{Relative treatment difference in time-to-first exacerbation}

The reductions in the risk of a first exacerbation between treatments were $40 \%-47 \%$ for shorter study durations ( $\leq 4$ months). Thereafter, the difference between treatments in time-to-first exacerbation decreased to $21 \%$ at 12 months (Figure 1D; Table S3).

\section{Exacerbations in moderate, severe, and very severe COPD}

Exacerbation rates per treatment were higher in more severe patients and more so with formoterol $(R R=0.64, R R=0.81$, and $R R=1.17$ exacerbations per patient and 12 months for moderate, severe, and very severe, respectively) than with budesonide/formoterol $(\mathrm{RR}=0.39, \mathrm{RR}=0.57$, and $\mathrm{RR}=0.91$, respectively) (Figure $\mathrm{S} 1$ ).

\section{AERs per treatment}

In patients treated with budesonide/formoterol, the AERs did not change over time for the three severity groups, though the $\mathrm{RR}$ levels differed with disease severity $(\mathrm{RR} \approx 0.45$, $\mathrm{RR} \approx 0.55$, and $\mathrm{RR} \approx 0.90$ exacerbations per patient and year for moderate, severe, and very severe, respectively). In patients treated with formoterol, the AERs decreased over time and more so for more severe disease. The RRs for decrease in AERs from 1-12 months were 0.84-0.64

Table I Demographic and baseline characteristics for all patients, stratified according to COPD disease severity group, treated with budesonide/formoterol or formoterol ${ }^{10-12}$

\begin{tabular}{|c|c|c|c|c|}
\hline \multirow[t]{2}{*}{ Characteristics } & \multirow{2}{*}{$\begin{array}{l}\text { All patients, } \\
n=2,345\end{array}$} & \multicolumn{3}{|c|}{ COPD disease severity } \\
\hline & & Moderate, $n=408$ & Severe, $n=1,325$ & Very severe, $n=612$ \\
\hline Age, years & $63.2(9.22)$ & $61.6(9.82)$ & $63.6(9.21)$ & $63.4(8.71)$ \\
\hline Male, n (\%) & $1,487(63)$ & $206(50)$ & $833(63)$ & $448(73)$ \\
\hline FEV, pre-BD, L & I.0I (0.4I) & $\mathrm{I} .38(0.43)$ & I.05 (0.33) & $0.69(0.26)$ \\
\hline 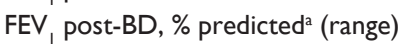 & $38.4(10.0-103.1)$ & $55.2(50.0-103.1)$ & $39.8(30.0-50.0)$ & $24.9(10.0-30.0)$ \\
\hline $\mathrm{FEV}_{\mathrm{I}} / \mathrm{FVC}$, ratio ${ }^{\mathrm{a}}$ (range) & $0.47(0.15-0.97)$ & $0.56(0.28-0.91)$ & $0.47(0.19-0.98)$ & $0.38(0.15-0.93)$ \\
\hline Pack-years ${ }^{a}$ (range) & $42.0(10.0-258.0)$ & $40.0(10.0-168.0)$ & $41.0(10.0-258.0)$ & $45.0(10.0-184.0)$ \\
\hline SGRQ total score & $55.8(16.9)$ & $52.7(16.8)$ & $55.2(17.3)$ & $59.4(15.6)$ \\
\hline Reliever use, inhalations/day & $4.5(4.0)$ & $3.6(3.2)$ & $4.2(3.7)$ & $5.8(4.7)$ \\
\hline
\end{tabular}

Notes: Data are presented as arithmetic mean (SD) unless otherwise stated. ${ }^{a}$ There were two patients with moderate COPD and one with severe COPD, who did not have an $\mathrm{FEV}_{\mathrm{I}} / \mathrm{FVC}<70 \%$ at run-in or randomization. Data from Rennard et al; ${ }^{10}$ Sharafkhaneh et al;" Tashkin et al. $^{12}$

Abbreviations: BD, bronchodilator; FEV , forced expiratory volume in I second; FVC, forced vital capacity; SD, standard deviation; SGRQ, St George's Respiratory Questionnaire. 
A

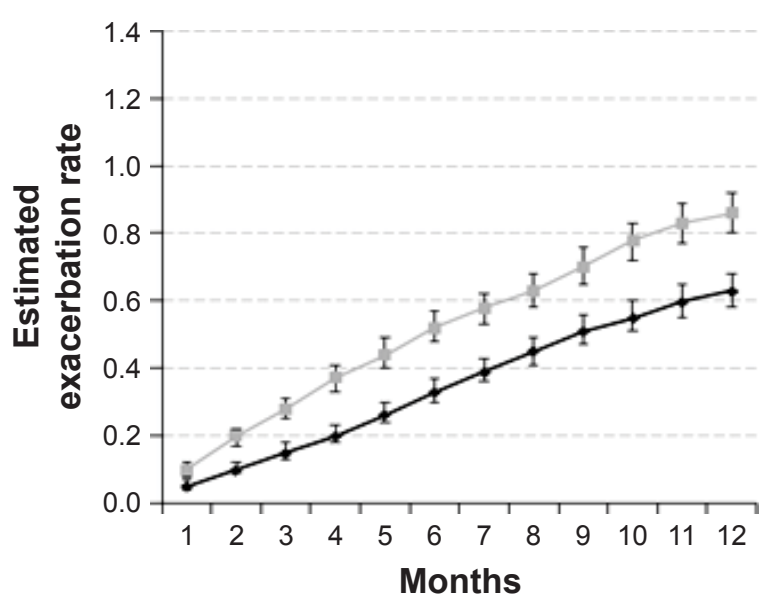

B

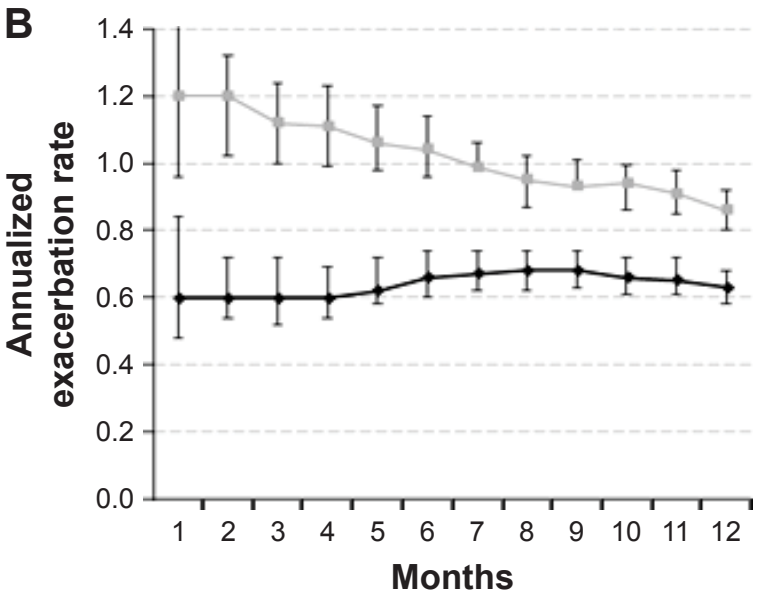

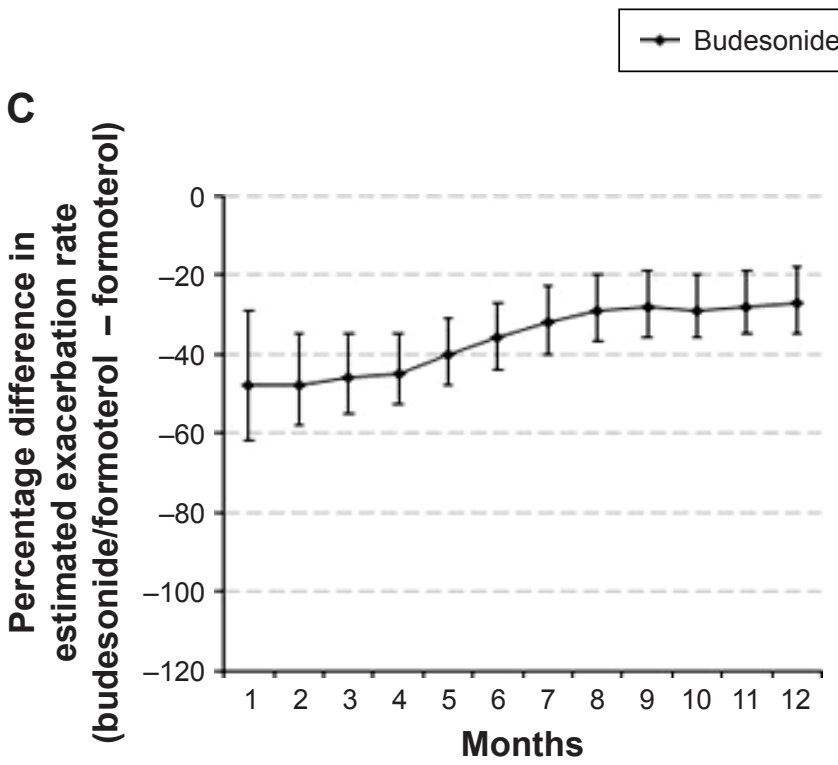

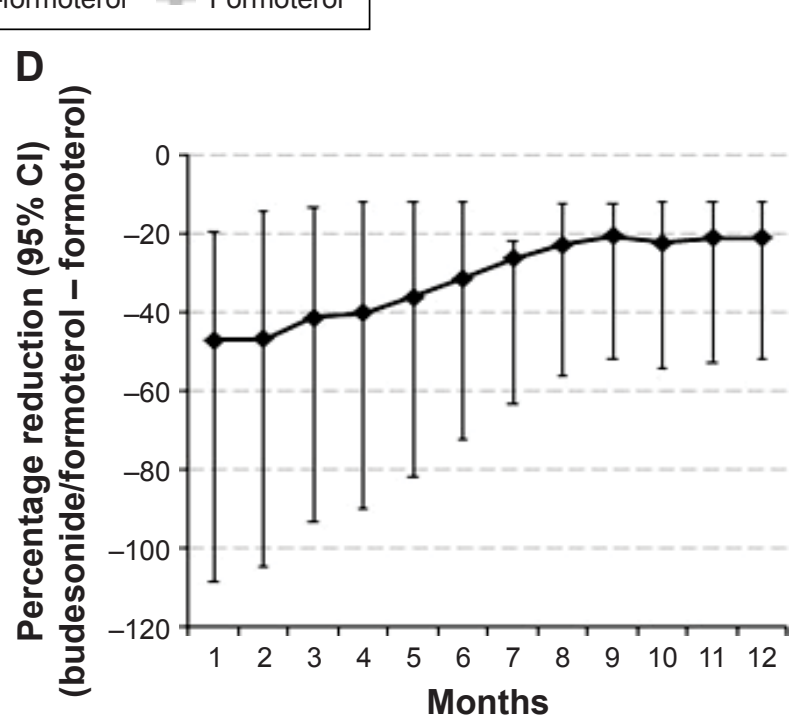

$=$ Formoterol

Figure I Exacerbations in all patients: (A) exacerbation rates for budesonide/formoterol and formoterol; (B) annualized exacerbation rates for budesonide/formoterol and formoterol; (C) percentage reduction in the exacerbation rates; (D) percentage reduction in time-to-first exacerbation.

Notes: Data in (A) and (B) are presented as estimated exacerbation rates with $95 \%$ confidence intervals. Data in (C) and (D) are presented as difference in estimated exacerbation rates with $95 \%$ confidence intervals in percentage.

Abbreviation: $\mathrm{Cl}$, confidence interval.

(reduction of $23.8 \%), 1.10-0.81(26.4 \%)$, and $1.68-1.17$ (30.4\%) for moderate, severe, and very severe COPD, respectively (Table 2 ).

\section{Relative treatment difference in exacerbation rate}

The exacerbation rate reduction of budesonide/formoterol versus formoterol over the first 4 months was similar across studies in moderate, severe, and very severe patients, ranging between 39\% and 51\% (Figure 2A; Table S2). In patients with moderate COPD, the initial difference in exacerbation rates $(39 \%-50 \%)$ was generally maintained for all study durations up to 12 months. However, in the severe and very severe COPD groups, the initial effect (ranging between $41 \%$ and 51\%) decreased to $29 \%$ and $22 \%$ at 12 months, respectively.
Relative treatment difference in time-to-first

\section{exacerbation}

Differences in time-to-first exacerbation between treatments were similar for moderate, severe, and very severe disease when study duration was short ( $\leq 4$ months), ranging from $38 \%$ to $49 \%$ (Figure $2 \mathrm{~B}$ ). Thereafter, the differences decreased for all three disease severities, with a trend for greater decrease in difference with increasing disease severity $(-25 \%[P=0.14],-23 \%[P<0.01]$, and $-18 \%[P=0.12])$ for moderate, severe, and very severe, respectively (Table S3).

\section{Discontinuation and differential dropout}

All discontinuations per study and treatment

The percentage of discontinuations was lower for budesonide/ formoterol than for formoterol alone. The difference in favor 
Table 2 Annualized exacerbation rates for budesonide/formoterol and formoterol according to COPD disease severity group

\begin{tabular}{|c|c|c|c|c|c|c|c|c|c|c|c|c|}
\hline \multirow{4}{*}{$\begin{array}{l}\text { Study } \\
\text { month }\end{array}$} & \multicolumn{12}{|c|}{ Annualized exacerbation rates } \\
\hline & \multicolumn{12}{|c|}{ Disease severity } \\
\hline & \multicolumn{4}{|c|}{ Moderate, $n=408$} & \multicolumn{4}{|c|}{ Severe, $n=1,325$} & \multicolumn{4}{|c|}{ Very severe, $n=612$} \\
\hline & $\begin{array}{l}\text { BUD/ } \\
\text { FOR }\end{array}$ & $95 \% \mathrm{Cl}$ & FOR & $95 \% \mathrm{Cl}$ & $\begin{array}{l}\text { BUD/ } \\
\text { FOR }\end{array}$ & $95 \% \mathrm{Cl}$ & FOR & $95 \% \mathrm{Cl}$ & $\begin{array}{l}\text { BUD/ } \\
\text { FOR }\end{array}$ & $95 \% \mathrm{Cl}$ & FOR & $95 \% \mathrm{Cl}$ \\
\hline I & 0.48 & $0.24-0.84$ & 0.84 & $0.48-1.44$ & 0.60 & $0.39-0.72$ & 1.08 & $0.84-1.32$ & 0.96 & $0.6-1.32$ & 1.68 & I.2-2.28 \\
\hline 2 & 0.48 & $0.30-0.78$ & 0.78 & $0.54-1.08$ & 0.54 & $0.42-0.66$ & 1.08 & $0.90-1.26$ & 0.90 & $0.66-1.2$ & $\mathrm{I} .74$ & $1.38-2.16$ \\
\hline 3 & 0.44 & $0.32-0.68$ & 0.84 & $0.60-1.12$ & 0.52 & $0.44-0.64$ & 1.04 & $0.92-1.24$ & 0.88 & $0.68-1.12$ & $\mathrm{I} .48$ & $1.20-1.76$ \\
\hline 4 & 0.45 & $0.33-0.66$ & 0.84 & $0.63-1.08$ & 0.54 & $0.45-0.66$ & 0.99 & $0.87-I .14$ & 0.84 & $0.66-1.05$ & 1.53 & $1.29-1.80$ \\
\hline 5 & 0.43 & $0.31-0.60$ & 0.82 & $0.65-1.06$ & 0.60 & $0.50-0.70$ & 0.98 & $0.86-1.10$ & 0.86 & $0.72-1.06$ & $\mathrm{I} .44$ & $1.22-1.68$ \\
\hline 6 & 0.44 & $0.34-0.62$ & 0.78 & $0.78-0.98$ & 0.60 & $0.52-0.70$ & 0.96 & $0.86-1.08$ & 0.96 & $0.82-1.14$ & $\mathrm{I} .44$ & $1.24-1.66$ \\
\hline 7 & 0.43 & $0.32-0.58$ & 0.74 & $0.58-0.91$ & 0.62 & $0.53-0.70$ & 0.93 & $0.82-1.03$ & 0.98 & $0.84-1.15$ & $\mathrm{I} .34$ & $1.33-1.52$ \\
\hline 8 & 0.42 & $0.33-0.57$ & 0.71 & $0.57-0.87$ & 0.62 & $0.54-0.69$ & 0.89 & $0.80-0.99$ & 0.98 & $0.84-1.13$ & 1.26 & I.10-I.44 \\
\hline 9 & 0.43 & $0.32-0.56$ & 0.69 & $0.57-0.85$ & 0.63 & $0.55-0.70$ & 0.88 & $0.80-0.98$ & 0.97 & $0.84-1.12$ & 1.24 & $|.09-| .4 \mid$ \\
\hline 10 & 0.41 & $0.31-0.53$ & 0.72 & $0.59-0.88$ & 0.61 & $0.54-0.68$ & 0.86 & $0.80-0.96$ & 0.95 & $0.83-1.1$ & 1.24 & I.08-1.40 \\
\hline 11 & 0.40 & $0.30-0.52$ & 0.64 & $0.57-0.84$ & 0.66 & $0.55-0.68$ & 0.84 & $0.83-0.93$ & 0.93 & $0.8 \mathrm{I}-\mathrm{I} .07$ & 1.21 & $1.07-1.37$ \\
\hline 12 & 0.39 & $0.30-0.50$ & 0.64 & $0.53-0.78$ & 0.57 & $0.5 \mathrm{I}-0.64$ & 0.81 & $0.73-0.89$ & 0.91 & $0.80-1.04$ & 1.17 & $1.03-1.32$ \\
\hline
\end{tabular}

Note: Data are presented as annualized exacerbation rates with $95 \%$ confidence intervals.

Abbreviations: BUD, budesonide; FOR, formoterol; $\mathrm{Cl}$, confidence interval.

of the budesonide/formoterol was $4.2 \%$ and $4.7 \%$ units in the two 12-month studies and $7.4 \%$ units in the 6-month study (Table 3).

Reason for discontinuations per treatment

Adverse event and withdrawal of consent were the two dominating reasons for discontinuations and differential dropout.
More patients discontinued on formoterol than budesonide/ formoterol due to adverse events ( $2.4 \%$ units) and withdrawal of consent (2.0\% units) (Table 4$)$.

CPDo

Discontinuations were higher for formoterol-treated patients than for budesonide/formoterol-treated patients
A

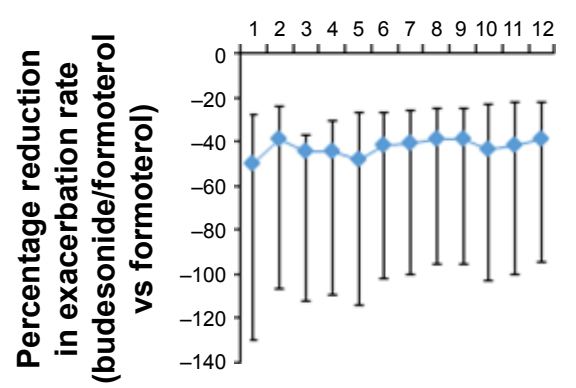

Moderate

B

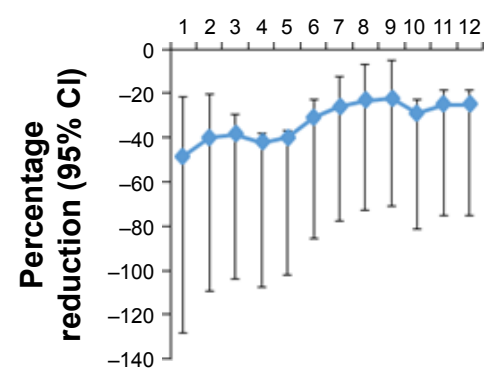

Moderate
Months

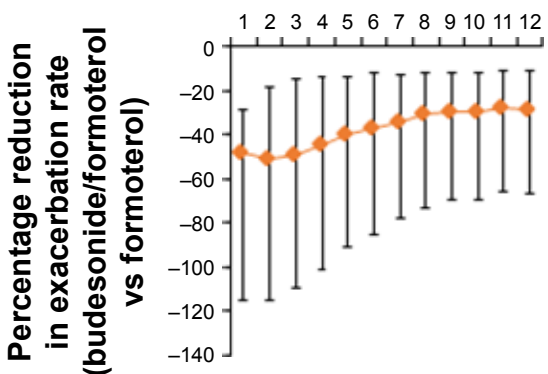

Severe

Months

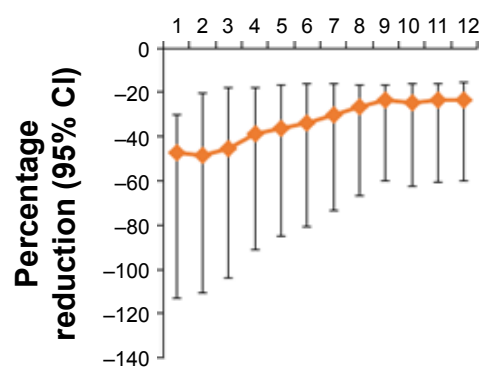

Severe
Months

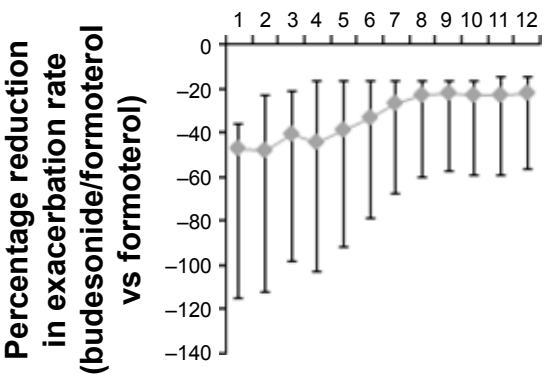

Very severe

Months

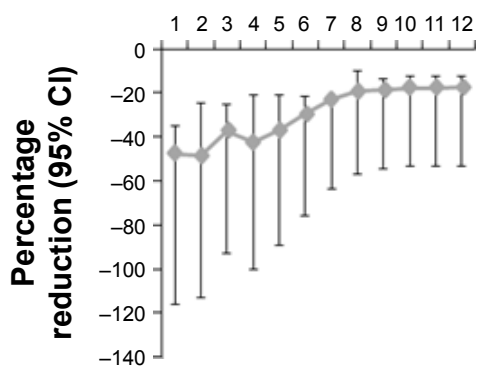

Very severe

Figure 2 Exacerbations over time in patients with moderate, severe, and very severe COPD: (A) treatment effect on exacerbation rate (\% change in favor of budesonide/ formoterol over formoterol only) for different study durations; (B) risk reduction of time-to-first exacerbation (percentage change in favor of budesonide/formoterol over formoterol only) for different study durations.

Note: Data are presented with $95 \%$ confidence intervals.

Abbreviation: $\mathrm{Cl}$, confidence interval. 
Table 3 All discontinuations and differential dropouts by study and treatment arm

\begin{tabular}{llll}
\hline Treatment & $\begin{array}{l}\text { Randomized } \\
(\mathbf{N})\end{array}$ & $\begin{array}{l}\text { Discontinuations } \\
(\mathbf{N})\end{array}$ & $\begin{array}{l}\text { Discontinuations/ } \\
\text { randomized (\%) }\end{array}$ \\
\hline BUD/FOR $^{\mathrm{a}}$ & 494 & 134 & 27.1 \\
$\mathrm{BUD}^{\mathrm{F}} \mathrm{FOR}^{\mathrm{b}}$ & 407 & 117 & 28.7 \\
$\mathrm{BUD}^{\mathrm{F}} \mathrm{FOR}^{\mathrm{c}, \mathrm{d}}$ & 277 & 39 & 14.1 \\
$\mathrm{FOR}^{\mathrm{a}}$ & 495 & 157 & 31.7 \\
FOR $^{\mathrm{b}}$ & 404 & 133 & 32.9 \\
FOR $^{\mathrm{c}, \mathrm{d}}$ & 284 & 61 & 21.5 \\
\hline
\end{tabular}

Notes: Data from ${ }^{\mathrm{a}}$ Rennard et al; 10 bSharafkhaneh et al;;1 cTashkin et al; ${ }^{12}$ d6-month study.

Abbreviations: BUD, budesonide; FOR, formoterol.

at months 2,3, and 4, and increased with disease severity (Figure 3). The pattern in moderate disease was not clear, since the number of discontinuations was the lowest and the cohort was the smallest.

Overall, this descriptive analysis indicated that the highest differential dropout occurred at months 2, 3, and 4 .

\section{Discontinuations}

In all patients, the time-to-discontinuation was significantly shorter with formoterol than with budesonide/formoterol from 2 to 12 months. This treatment difference decreased with study duration $(35 \%, 30 \%, 26 \%$, and $22 \%$ at 3,6 , 9 , and 12 months, respectively). We observed a similar pattern with moderate and severe COPD, moving from treatment differences of $32 \%$ and $34 \%$ at 3 months to $15 \%$ at 12 months. In patients with moderate disease, no significant difference between treatments could be detected, whereas in patients with severe COPD, there was a statistically significant difference in time-to-first discontinuation at 3-, 4-, 5-, and 6-month study durations in favor of the budesonide/formoterol group. The very severe group showed, however, significant treatment difference from 3 to 12 months. This treatment difference was high over the whole study duration (34\%-38\% from 3 to 12 months) (Figure 4; Table S4).

\section{Composite of ExDo}

ExDo, the composite of exacerbations and discontinuations, increased the number of events over that of exacerbations alone, both in all patients and in all three severity groups. ExDo also showed more consistent results in more severe COPD, where the differential dropout was more prominent. For example, the relative treatment difference in time-toexacerbation was $18 \%-19 \%$ and not significant in analyses of 7- to 12-month study durations, whereas relative treatment difference in time-to-ExDo was significant for all these study durations with a $21 \%-23 \%$ difference in favor of budesonide/ formoterol (Table 5).

\section{Discussion}

Our results demonstrate that both disease severity and study duration influence exacerbation outcomes in double-blind RCTs in COPD. This effect is particularly apparent in patients with severe/very severe COPD and in studies that are longer than 4 months' duration, where early differential dropout resulted in a "healthy survivor effect". This effect changed the composition of the study groups and tended to reduce the effect of therapy over time.

The impact of differential dropout on long-term efficacy outcomes in COPD has been recognized as a potential source of bias, and several studies have highlighted this problem. ${ }^{7,8,14,15}$ These studies had all a follow-up of 3-4 years. However, the consequences for shorter term studies ( $\leq 12$ months), a commonly used study design in phases II-III and for regulatory purposes, has not been formally investigated. This retrospective analysis of moderate-to-very-severe COPD in three RCTs ${ }^{10-12}$ of 6-12 months' duration showed over time a marked loss in exacerbation difference between the two treatments: budesonide/formoterol and formoterol. This loss of treatment difference was increased by study duration and in more severe COPD, but these effects were almost negligible in moderate COPD. Of importance, the time-tofirst exacerbation was more impacted than exacerbation rates,

Table 4 Reasons for discontinuations per treatment arm

\begin{tabular}{|c|c|c|c|c|c|}
\hline $\begin{array}{l}\text { Reason for } \\
\text { discontinuation }\end{array}$ & BUD/FOR (N) & $\begin{array}{l}\text { BUD/FOR, reason/ } \\
\text { randomized (\%) }\end{array}$ & FOR (N) & $\begin{array}{l}\text { FOR, reason/ } \\
\text { randomized (\%) }\end{array}$ & $\Delta$ BUD/FOR-FOR (\%) \\
\hline Adverse events & 120 & 10.2 & 149 & 12.6 & -2.4 \\
\hline Consent withdrawn & 92 & 7.8 & 116 & 9.8 & -2.0 \\
\hline Others & 40 & 3.4 & 41 & 3.5 & -0.1 \\
\hline Eligibility & 17 & 1.4 & 26 & 2.2 & -0.8 \\
\hline Lost to follow-up & 21 & 1.8 & 19 & 1.6 & +0.2 \\
\hline Total & 290 & 24.6 & 351 & 29.7 & -5.1 \\
\hline
\end{tabular}

Note: $\triangle B U D / F O R-F O R$, percentage unit difference for BUD/FOR-FOR.

Abbreviations: BUD, budesonide; FOR, formoterol. 


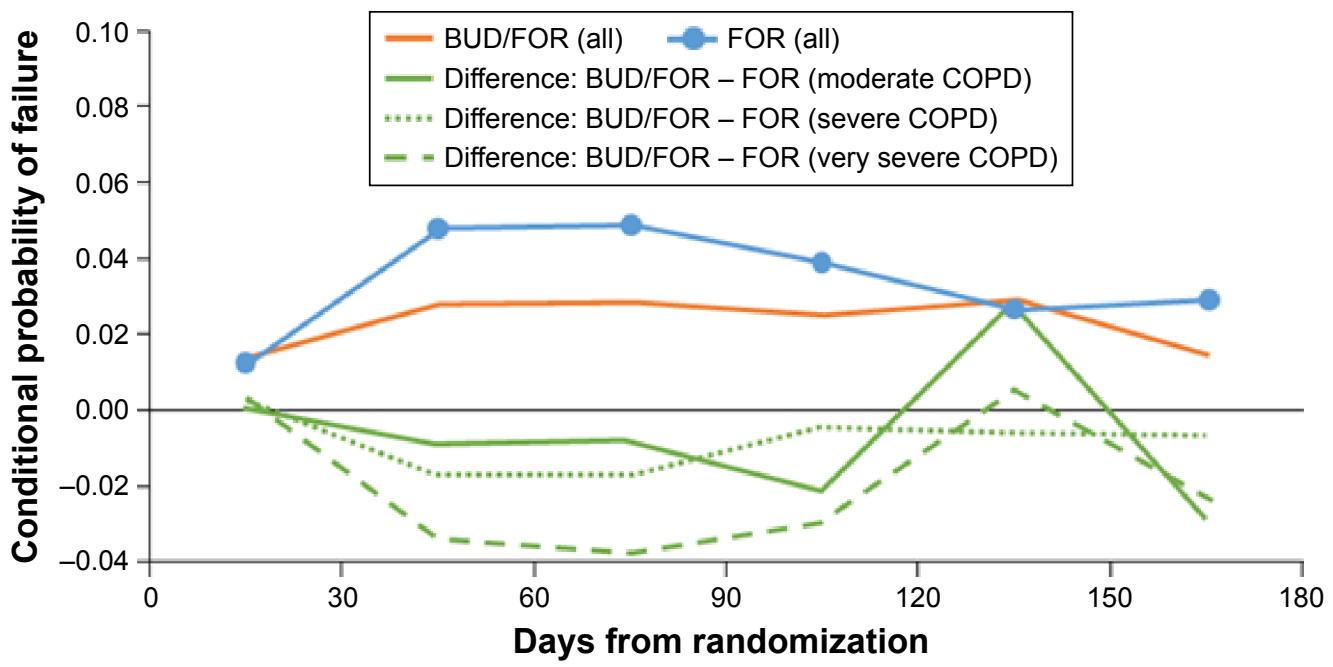

Figure 3 Discontinuations for budesonide/formoterol and formoterol in all patients, and difference in discontinuations for budesonide/formoterol versus formoterol in patients with moderate, severe, and very severe COPD.

Note: No data are presented after 6 months as the number of patients that drop out (one study 6 months) and the number of discontinuations per month decrease. Abbreviations: BUD/FOR, budesonide/formoterol; FOR, formoterol.

and the differential dropout preceded the loss of treatment effect on exacerbations. We believe these results will further raise the awareness of how important study methodology, selection of patients, and calculation of sample size are in exacerbation studies.

In the budesonide/formoterol treatment arm, the AERs were similar for shorter and longer study durations, whereas

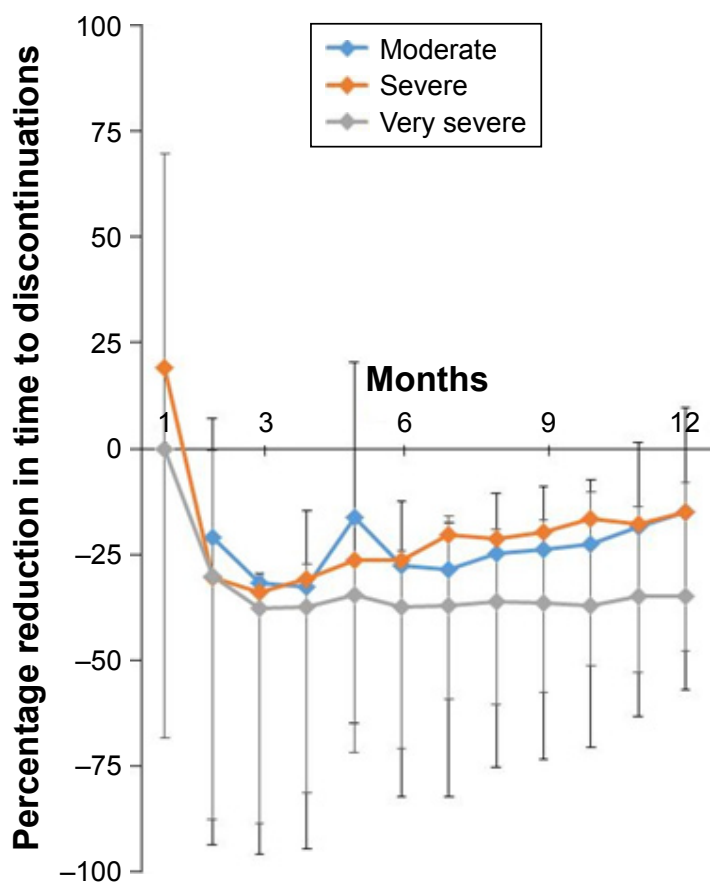

Figure 4 Percentage reduction in time to discontinuation for budesonide/formoterol compared with formoterol according to COPD disease severity.

Notes: Data are presented with $95 \%$ confidence intervals. Four discontinuations (three on formoterol and one on budesonide/formoterol) at I month in patients with moderate COPD. they decreased over time with monotherapy formoterol, indicating differential effects of these treatments. Our shorter term data support those of Vestbo et $a 1,{ }^{7}$ reporting that differential withdrawal over a 3 -year period resulted in a reduction in AERs from 6.8 to 0.9 in placebo and from 3.0 to 0.8 with salmeterol/fluticasone. These data together, showing a decrease in AERs over time, indicate that weaker treatments may lose more patients over time, who are more exacerbation prone than those in the more active comparator arm. We demonstrate that this effect can already be seen during the first 6 months in very severe patients.

The analyses of the relative treatment difference in exacerbation rate also demonstrate this time-dependent effect. In the whole population, this was already evident after $>4$ months' study duration. A $45 \%-48 \%$ difference in studies of short duration was reduced to $27 \%-29 \%$ in the studies over 9-12 months. The time-to-first exacerbation analyses showed similar results, with a treatment difference being $40 \%-47 \%$ in the first 3 months, decreasing to $21 \%-22 \%$ in months $9-12$. The most likely explanation for the decrease in relative treatment difference is that the more severe patients randomized to formoterol are more vulnerable to early discontinuation than similarly severe patients in the budesonide/formoterol arm. These data may also explain why a 3 -month study by Welte et a $\mathrm{a}^{16}$ could show a $60 \%$ treatment difference between budesonide/formoterol and placebo and importantly with no differential dropout.

The impact of COPD severity on exacerbation outcomes has been investigated in many studies, but two studies specifically addressed the moderate, severe, and very 
Table 5 Time-to-ExDo analyses for budesonide/formoterol versus formoterol in all patients and according to COPD disease severity group

\begin{tabular}{|c|c|c|c|c|c|}
\hline \multirow{3}{*}{$\begin{array}{l}\text { Study } \\
\text { month }\end{array}$} & \multicolumn{5}{|l|}{ Time-to-ExDo } \\
\hline & \multicolumn{2}{|c|}{ All patients, $n=2,345$} & \multicolumn{3}{|l|}{ Disease severity } \\
\hline & & $P$-value & Moderate, $n=408$ & Severe, $n=I, 325$ & Very severe, $n=6 \mid 2$ \\
\hline I & $0.570(0.429,0.759)$ & 0.0001 & $0.5 \mid 4(0.220,1.202)$ & $0.589(0.395,0.879)^{*}$ & $0.558(0.350,0.889)^{*}$ \\
\hline 2 & $0.571(0.468,0.697)$ & $<0.0001$ & $0.690(0.385,1.236)$ & $0.552(0.4 I 7,0.73 \mathrm{I})^{* * *}$ & $0.55 \mathrm{I}(0.398,0.764)^{* *}$ \\
\hline 3 & $0.588(0.497,0.696)$ & $<0.000 \mathrm{I}$ & $0.64 \mathrm{I}(0.4 \mathrm{II}, 0.999)^{*}$ & $0.555(0.438,0.704)^{* * *}$ & $0.606(0.456,0.806)^{* *}$ \\
\hline 4 & $0.610(0.525,0.709)$ & $<0.0001$ & $0.623(0.42 \mathrm{I}, 0.92 \mathrm{I})^{*}$ & $0.623(0.504,0.770)^{* * *}$ & $0.576(0.446,0.743)^{* * * *}$ \\
\hline 5 & $0.668(0.58 \mathrm{I}, 0.768)$ & $<0.0001$ & $0.69 \mathrm{I}(0.48 \mathrm{I}, 0.993)^{*}$ & $0.670(0.55 \mathrm{I}, 0.8 \mathrm{I} 5)^{* * * *}$ & $0.639(0.503,0.81 \mathrm{I})^{* *}$ \\
\hline 6 & $0.703(0.617,0.802)$ & $<0.0001$ & $0.727(0.518,1.022)$ & $0.692(0.576,0.832)^{* * *}$ & $0.692(0.552,0.867)^{* *}$ \\
\hline 7 & $0.747(0.659,0.848)$ & $<0.000$ I & $0.765(0.553,1.059)$ & $0.733(0.615,0.875)^{* *}$ & $0.743(0.597,0.924)^{*}$ \\
\hline 8 & $0.773(0.683,0.874)$ & $<0.0001$ & $0.774(0.563,1.064)$ & $0.756(0.636,0.898) * *$ & $0.780(0.630,0.965)^{*}$ \\
\hline 9 & $0.787(0.698,0.887)$ & $<0.0001$ & $0.786(0.576, \mathrm{I} .07 \mathrm{I})$ & $0.779(0.660,0.920)^{* *}$ & $0.780(0.633,0.959)^{*}$ \\
\hline 10 & 0.777 (0.69I, 0.874) & $<0.0001$ & $0.776(0.574, \mathrm{I} .05 \mathrm{I})$ & $0.769(0.653,0.904)^{* *}$ & $0.773(0.629,0.950)^{*}$ \\
\hline 11 & 0.788 (0.70I, 0.884) & $<0.0001$ & $0.789(0.585,1.065)$ & $0.776(0.66 \mathrm{I}, 0.9 \mathrm{II})^{* *}$ & $0.786(0.64 \mathrm{I}, 0.964)^{*}$ \\
\hline 12 & $0.79 \mid(0.705,0.887)$ & $<0.0001$ & $0.799(0.593,1.078)$ & $0.778(0.664,0.911)^{* *}$ & $0.788(0.644,0.964)^{*}$ \\
\hline
\end{tabular}

Notes: Data are presented as hazard ratios and $95 \%$ confidence intervals. $* P<0.05 ; * * P<0.005 ; * * * P<0.000$ I. BUD/FOR versus FOR.

Abbreviations: ExDo, exacerbation and discontinuation; BUD, budesonide; FOR, formoterol.

severe COPD subgroups. ${ }^{15,17}$ Our approach extends their work by showing that the impact on exacerbations occurs early ( $\leq 12$ months). In the three severity groups, we found that the AERs for the two treatments were consistent with those from the whole group, that is, budesonide/formoterol showed constant values over time irrespective of severity, whereas formoterol treatment was accompanied by a reduction in annualized exacerbations over time and with increased severity. As a consequence, the treatment differences with respect to the exacerbation rate decreased over time and with severity. These data support the assumption that more severe and unstable patients discontinue earlier in a treatment arm, where efficacy is not sufficient for the severity stage. The severity of COPD had less (or minimal) impact on studies with shorter duration ( $\leq 4$ months), while it was marked in studies beyond 5-6 months, and in studies involving patients with severe and very severe COPD. For these patients, the treatment effect decreased over time, from $41 \%-51 \%$ for shorter durations to $29 \%$ and $22 \%$, respectively, at 12 months' duration. However, the treatment difference in moderate disease remained unaffected over time (about $40 \%-45 \%$ difference in favor of budesonide/ formoterol). The results from the time-to-first exacerbation in the three severity groups paralleled our findings from the whole group. However, this statistical method seemed to be less powerful and sensitive to disease severity than using exacerbation rates. For example, the moderate severity group showed loss in effect over time for time-to-first exacerbation (but not with exacerbation rate) and the very severe group showed an initial significant difference in effect, whereas the effect was nonsignificant in study durations of 6-12 months (but not with exacerbation rate). Similar findings with time-to-first exacerbation analyses have been observed in corticosteroid withdrawal studies ${ }^{18}$ and may reflect a greater likelihood of frequent exacerbators to drop out early.

As expected, discontinuations in COPD studies were high, especially as our patients predominantly had severe-to-verysevere COPD. We also found a higher discontinuation in the formoterol group, likely related to more treatment failures and/or more long-acting beta agonist (LABA)-related adverse events in the LABA-only group. As both groups used LABA and general adverse events were similar, it can be speculated that the differential dropout is related to a weaker effect of LABA alone. Two explanations predominated as causes of differential dropout: adverse event and withdrawal of informed consent. Both may be due to disease worsening or perceived lack of benefit. By comparison, reasons such as eligibility for the study, loss to follow-up, and "others" were more comparable between treatments.

To understand the time course of the differential dropout, we performed an exploratory analysis, investigating conditional probability to dropout (CPDo) at a certain month. The all-patient analysis showed that fewer patients discontinued during months 2,3 , and 4 on budesonide/ formoterol compared with formoterol alone. In the very severe group, a clear difference in discontinuation frequency was seen during months $2-5$. Though the group with moderate COPD also indicated a difference, the lower number of discontinuations due to less severe disease and longer time in the study made interpretation difficult. 
The analysis of time-to-first discontinuations showed a large difference between active and less active treatment in study durations of $2-4$ months $(\sim 35 \%)$. Thereafter, the difference between treatments for all patients, moderate and severe COPD decreased with longer study durations $(15 \%-20 \%$ for studies $\geq 9$ months), indicating a decrease in differential dropout over time. The very severe COPD group showed a different pattern with a high difference between treatments, irrespective of study duration (38\%-34\%). These analyses support the CPDo data that the differential dropout effects appear early and before the change of treatment differences in exacerbations are noted. In addition, and in line with CPDo, the impact is more pronounced and longer lasting in very severe COPD.

This post hoc analysis has some limitations. Patient numbers across the three severity groups comprised a skewed distribution, due to the original studies not being designed around severities; the limited number of patients in the moderate COPD group $(\mathrm{n}=408)$ may have affected analysis, especially when compared to the severe COPD group $(n=1,325)$; patients included in the original trials had a history of $\geq 1$ COPD exacerbation in the previous year so our results are not generalizable to all patients with COPD. The present analysis only investigated the addition of budesonide to formoterol, and our results should, therefore, be validated with other drug classes. Finally, analyses such as the one presented cannot be generalized to differential dropout due to differences in side-effect profiles.

In conclusion, our data indicate that the relative treatment differences in exacerbation rates over a whole study can vary by threefold. As the benefit of an effective intervention may be underestimated in longer studies, this may have implications for drug development. Our data highlight the importance of study design, patient selection, and study duration, and show that subtle differences in these parameters can make comparisons between studies challenging and questionable. Future studies of new agents designed to modify exacerbation outcomes in COPD may benefit from adopting a shorter focused design, which minimizes the effect of differential dropout, an approach already shown to be effective in clinical trials of COPD. ${ }^{16}$

\section{Acknowledgments}

This study was funded by AstraZeneca. The authors would like to thank Shaun Foley and Clair Clowes of inScience Communications, Springer Healthcare, who provided editing assistance, funded by AstraZeneca.

\section{Author contributions}

All authors contributed to data interpretation, and conceiving, writing, and revising of the manuscript. All authors approved the final version of the manuscript. ML was responsible for statistical analyses. GE, the corresponding author, had full access to all the data in the study and had final responsibility for the decision to submit for publication.

\section{Disclosure}

GE consults for Airsonett, ALK, Almirall, MVIC, and Novartis. He is an ex-employee of AstraZeneca (March 2013).

PMC is a board member for Boehringer Ingelheim, the Department of Health Respiratory Programme Board, GlaxoSmithKline, and Nycomed. He has been a consultant for Novartis and provided expert testimony for Forest. PMC has received honoraria for advising on the conduct and analysis of clinical trial data from AstraZeneca, Boehringer Ingelheim, GlaxoSmithKline, Novartis, and Nycomed. He has also spoken at meetings supported by these companies. Support for travel to meetings has been provided by AstraZeneca.

CRJ is an advisory board member for AstraZeneca, Boehringer Ingelheim, GlaxoSmithKline, Merck Limited, and Novartis, and a consultant for AstraZeneca, GlaxoSmithKline, Pieris, and Chiesi. Educational presentations have been developed for AstraZeneca, Boehringer Ingelheim, GlaxoSmithKline, and Novartis, with honoraria paid to CRJ or her institution. Lectures have been presented on behalf of AstraZeneca, Boehringer Ingelheim, GlaxoSmithKline, and Novartis. Support for travel to advisory meetings has been provided by AstraZeneca, Novartis, and Boehringer Ingelheim.

ARA is a consultant and speaker for AstraZeneca, Bayer Pharma, Boehringer Ingelheim, Sunovion Pharma, GlaxoSmithKline, and Pfizer, and has received honoraria from these companies. Educational presentations have been developed for AstraZeneca, Bayer Pharma, Boehringer Ingelheim, Sunovion Pharma, GSK, and Pfizer. University of Texas Health Science Center at San Antonio has received money for research to perform clinical trials. Support for travel to meetings has also been provided by AstraZeneca.

$\mathrm{BJM}$ is an advisory board member for Aerocrine, AstraZeneca, Boehringer Ingelheim, CSL Bering, Forest, Novartis, and Theravance, and a consultant for Astellas, Forest, and Chiesi. Clinical trial data have been reviewed for Spiration, with grants received and controlled by National Jewish Health from AstraZeneca, Boehringer Ingelheim, 
GlaxoSmithKline, Forest, MedImmune, Nabi, National Institutes of Health, Pfizer, and Sunovion. Lectures have been presented on behalf of Boehringer Ingelheim and GlaxoSmithKline. Educational presentations and programs have been developed (Carden Jennings, Cleveland Clinic, Consensus Medical, Foundation for Improving Patient Outcomes, Hybrid Communications, Integrity, Intellisphere, Medscape, National Jewish Health, Projects in Knowledge, SPIRE, Synapse, and WebMD). Royalties have been received from Up-To-Date. BJM has been a speaker for educational programs at Abbott, the American Academy of Family Practice, the American College of Chest Physicians, and the American Thoracic Society. Support for travel to meetings has also been provided by AstraZeneca.

The University of Groningen has received honoraria for DSP advising on the conduct and analysis of clinical trial data from AstraZeneca, Nycomed, and Teva, as well as for lectures at meetings supported by AstraZeneca, Chiesi, GlaxoSmithKline, Nycomed, and Teva. The University of Groningen has received money for research by unrestricted educational grants from AstraZeneca and Chiesi. AstraZeneca, Boehringer Ingelheim, Chiesi, GlaxoSmithKline, and Nycomed have provided support for travel to meetings.

ML and MF are employees of AstraZeneca and own stocks within the company.

\section{References}

1. Friedman L, Furbeg C, Demets D. Fundamentals of Clinical Trials. 3rd ed. New York, NY: Springer; 1998.

2. Calverley PM, Anderson JA, Celli B, et al. Salmeterol and fluticasone propionate and survival in chronic obstructive pulmonary disease. $N$ Engl J Med. 2007;356(8):775-789.

3. Calverley P, Pauwels R, Vestbo J, et al. Combined salmeterol and fluticasone in the treatment of chronic obstructive pulmonary disease: a randomised controlled trial. Lancet. 2003;361(9356):449-456.

4. Dransfield MT, Bourbeau J, Jones PW, et al. Once-daily inhaled fluticasone furoate and vilanterol versus vilanterol only for prevention of exacerbations of COPD: two replicate double-blind, parallel-group, randomised controlled trials. Lancet Respir Med. 2013;1(3):210-223.
5. Wilt TJ, Niewoehner D, MacDonald R, Kane RL. Management of stable chronic obstructive pulmonary disease: a systematic review for a clinical practice guideline. Ann Intern Med. 2007;147(9):639-653.

6. Suissa S, Ernst P, Vandemheen KL, Aaron SD. Methodological issues in therapeutic trials of COPD. Eur Respir J. 2008;31(5):927-933.

7. Vestbo J, Anderson JA, Calverley PM, et al. Bias due to withdrawal in long-term randomised trials in COPD: evidence from the TORCH study. Clin Respir J. 2011;5(1):44-49.

8. Calverley PM, Spencer S, Willits L, Burge PS, Jones PW. Withdrawal from treatment as an outcome in the ISOLDE study of COPD. Chest. 2003;124(4):1350-1356.

9. Kesten S, Plautz M, Piquette CA, Habib MP, Niewoehner DE. Premature discontinuation of patients: a potential bias in COPD clinical trials. Eur Respir J. 2007;30(5):898-906.

10. Rennard SI, Tashkin DP, McElhattan J, et al. Efficacy and tolerability of budesonide/formoterol in one hydrofluoroalkane pressurized metereddose inhaler in patients with chronic obstructive pulmonary disease: results from a 1-year randomized controlled clinical trial. Drugs. 2009; 69(5):549-565.

11. Sharafkhaneh A, Southard JG, Goldman M, Uryniak T, Martin UJ. Effect of budesonide/formoterol pMDI on COPD exacerbations: a doubleblind, randomized study. Respir Med. 2012;106(2):257-268.

12. Tashkin DP, Rennard SI, Martin P, et al. Efficacy and safety of budesonide and formoterol in one pressurized metered-dose inhaler in patients with moderate to very severe chronic obstructive pulmonary disease: results of a 6-month randomized clinical trial. Drugs. 2008;68(14): 1975-2000.

13. GOLD. Global Strategy for the Diagnosis, Management and Prevention of Chronic Obstructive Pulmonary Disease. [updated; 2015. cited]. Available from: http://www.goldcopd.org/uploads/users/files/ GOLD_Report_2015_Feb18.pdf.

14. Decramer M, Molenberghs G, Liu D, et al. Premature discontinuation during the UPLIFT study. Respir Med. 2011;105(10):1523-1530.

15. Jenkins CR, Jones PW, Calverley PM, et al. Efficacy of salmeterol/ fluticasone propionate by GOLD stage of chronic obstructive pulmonary disease: analysis from the randomised, placebo-controlled TORCH study. Respir Res. 2009;10:59.

16. Welte T, Miravitlles M, Hernandez P, et al. Efficacy and tolerability of budesonide/formoterol added to tiotropium in patients with chronic obstructive pulmonary disease. Am J Respir Crit Care Med. 2009; 180(8):741-750.

17. Decramer M, Celli B, Kesten S, et al. Effect of tiotropium on outcomes in patients with moderate chronic obstructive pulmonary disease (UPLIFT): a prespecified subgroup analysis of a randomised controlled trial. Lancet. 2009;374(9696):1171-1178.

18. Watz H, Tetzlaff $\mathrm{K}$, Wouters EF, et al. Blood eosinophil count and exacerbations in severe chronic obstructive pulmonary disease after withdrawal of inhaled corticosteroids: a post-hoc analysis of the WISDOM trial. Lancet Respir Med. 2016;4(5):390-398. 


\section{Supplementary materials}

Table SI Annualized exacerbation rates for budesonide/formoterol and formoterol for all patients

\begin{tabular}{|c|c|c|c|c|}
\hline \multirow[t]{3}{*}{ Study month } & \multicolumn{4}{|c|}{ Annualized exacerbation rates } \\
\hline & \multicolumn{4}{|c|}{ All patients, $n=2,345$} \\
\hline & BUD/FOR & $95 \% \mathrm{Cl}$ & FOR & $95 \% \mathrm{Cl}$ \\
\hline $\mathrm{I}$ & 0.60 & $0.48-0.84$ & 1.20 & $0.96-1.44$ \\
\hline 2 & 0.60 & $0.54-0.72$ & 1.20 & $1.02-1.32$ \\
\hline 3 & 0.60 & $0.52-0.72$ & 1.12 & I.0-I.24 \\
\hline 4 & 0.60 & $0.54-0.69$ & 1.11 & $0.99-1.23$ \\
\hline 5 & 0.62 & $0.58-0.72$ & 1.06 & $0.98-1.17$ \\
\hline 6 & 0.66 & $0.60-0.74$ & 1.04 & $0.96-1.14$ \\
\hline 7 & 0.67 & $0.62-0.74$ & 0.99 & $0.99-1.06$ \\
\hline 8 & 0.68 & $0.62-0.74$ & 0.95 & $0.87-1.02$ \\
\hline 9 & 0.68 & $0.63-0.74$ & 0.93 & $0.93-1.01$ \\
\hline 10 & 0.66 & $0.6 \mathrm{I}-0.72$ & 0.94 & $0.86-.996$ \\
\hline II & 0.65 & $0.6 I-0.72$ & 0.91 & $0.85-0.98$ \\
\hline 12 & 0.63 & $0.58-0.68$ & 0.86 & $0.80-0.92$ \\
\hline
\end{tabular}

Abbreviations: BUD, budesonide; $\mathrm{Cl}$, confidential interval; FOR, formoterol.

Table S2 Exacerbation rate ratios for budesonide/formoterol compared with formoterol in all patients and in the three COPD disease severity groups

\begin{tabular}{|c|c|c|c|c|c|c|c|c|}
\hline \multirow{4}{*}{$\begin{array}{l}\text { Study } \\
\text { month }\end{array}$} & \multicolumn{8}{|c|}{ Exacerbation rate ratios } \\
\hline & \multicolumn{2}{|l|}{ All patients, $n=2,345$} & \multicolumn{6}{|l|}{ Disease severity } \\
\hline & & \multirow[b]{2}{*}{$P$-value } & \multicolumn{2}{|c|}{ Moderate COPD, $n=408$} & \multicolumn{2}{|c|}{ Severe COPD, n=I,325 } & \multicolumn{2}{|c|}{ Very severe COPD, $n=6 \mid 2$} \\
\hline & & & & $P$-value & & $P$-value & & $P$-value \\
\hline I & $-0.48(-0.62,-0.29)$ & $<0.0001$ & $-0.50(-0.80,0.22)$ & 0.1266 & $-0.48(-0.67,-0.19)$ & 0.0036 & $-0.47(-0.68,-0.11)$ & 0.0152 \\
\hline 2 & $-0.48(-0.58,-0.35)$ & $<0.0001$ & $-0.39(-0.68,0.15)$ & 0.1270 & $-0.5 \mathrm{I}(-0.64,-0.32)$ & $<0.0001$ & $-0.48(-0.64,-0.25)$ & 0.0004 \\
\hline 3 & $-0.46(-0.55,-0.35)$ & $<0.0001$ & $-0.45(-0.67,-0.08)$ & 0.0231 & $-0.49(-0.6 \mathrm{I},-0.34)$ & $<0.0001$ & $-0.4 \mathrm{I}(-0.57,-0.20)$ & 0.0008 \\
\hline 4 & $-0.45(-0.53,-0.35)$ & $<0.0001$ & $-0.45(-0.65,-0.14)$ & 0.0091 & $-0.45(-0.56,-0.3 \mathrm{I})$ & $<0.0001$ & $-0.45(-0.58,-0.28)$ & $<0.0001$ \\
\hline 5 & $-0.40(-0.48,-0.31)$ & $<0.0001$ & $-0.48(-0.66,-0.21)$ & 0.0021 & $-0.40(-0.5 \mathrm{I},-0.26)$ & $<0.0001$ & $-0.39(-0.53,-0.22)$ & $<0.0001$ \\
\hline 6 & $-0.36(-0.44,-0.27)$ & $<0.0001$ & $-0.42(-0.60,-0.15)$ & 0.0055 & $-0.37(-0.48,-0.25)$ & $<0.0001$ & $-0.33(-0.46,-0.16)$ & 0.0004 \\
\hline 7 & $-0.32(-0.40,-0.23)$ & $<0.0001$ & $-0.41(-0.59,-0.15)$ & 0.0043 & $-0.34(-0.44,-0.21)$ & $<0.0001$ & $-0.27(-0.4 I,-0.10)$ & 0.0037 \\
\hline 8 & $-0.29(-0.37,-0.20)$ & $<0.0001$ & $-0.39(-0.57,-0.14)$ & 0.0055 & $-0.31(-0.42,-0.19)$ & $<0.000 \mathrm{I}$ & $-0.23(-0.37,-0.06)$ & 0.0121 \\
\hline 9 & $-0.28(-0.36,-0.19)$ & $<0.0001$ & $-0.39(-0.57,-0.14)$ & 0.0045 & $-0.30(-0.40,-0.18)$ & $<0.0001$ & $-0.22(-0.36,-0.05)$ & 0.0145 \\
\hline 10 & $-0.29(-0.36,-0.20)$ & $<0.0001$ & $-0.44(-0.59,-0.21)$ & 0.0007 & $-0.30(-0.40,-0.18)$ & $<0.0001$ & $-0.23(-0.36,-0.06)$ & 0.0082 \\
\hline II & $-0.28(-0.35,-0.19)$ & $<0.0001$ & $-0.42(-0.58,-0.20)$ & 0.0009 & $-0.28(-0.38,-0.17)$ & $<0.000$ I & $-0.23(-0.36,-0.08)$ & 0.0052 \\
\hline 12 & $-0.27(-0.35,-0.19)$ & $<0.0001$ & $-0.39(-0.56,-0.17)$ & 0.0017 & $-0.29(-0.38,-0.18)$ & $<0.0001$ & $-0.22(-0.35,-0.07)$ & 0.0063 \\
\hline
\end{tabular}

Note: Data are presented as reduction in the exacerbation rate ratio and $95 \%$ confidence intervals.

Table S3 Time-to-first exacerbation for budesonide/formoterol and formoterol in all patients and according to COPD disease severity group

\begin{tabular}{|c|c|c|c|c|c|}
\hline \multirow{3}{*}{$\begin{array}{l}\text { Study } \\
\text { month }\end{array}$} & \multicolumn{5}{|c|}{ Time-to-first exacerbation } \\
\hline & \multicolumn{2}{|c|}{ All patients, $n=2,345$} & \multicolumn{3}{|l|}{ Disease severity } \\
\hline & & $P$-value & Moderate COPD, n=408 & Severe COPD, n=I,325 & Very severe COPD, $n=6 \mid 2$ \\
\hline I & $0.528(0.385,0.723)$ & $<0.0001$ & $0.513(0.207,1.272)$ & $0.53 \mathrm{I}(0.340,0.830)^{*}$ & $0.525(0.316,0.873)^{*}$ \\
\hline 2 & $0.532(0.420,0.673)$ & $<0.0001$ & $0.601(0.303,1.194)$ & $0.519(0.373,0.722)^{* * *}$ & $0.519(0.352,0.765)^{* *}$ \\
\hline 3 & $0.586(0.478,0.718)$ & $<0.0001$ & $0.615(0.347,1.089)$ & $0.547(0.4 \mid 2,0.726)^{* * *}$ & $0.625(0.443,0.88 \mathrm{I})^{*}$ \\
\hline 4 & $0.599(0.499,0.719)$ & $<0.0001$ & $0.578(0.349,0.957)^{*}$ & $0.613(0.476,0.790) * *$ & $0.575(0.422,0.782)^{* *}$ \\
\hline 5 & $0.639(0.540,0.758)$ & $<0.0001$ & $0.603(0.374,0.974)^{*}$ & $0.64 \mathrm{I}(0.508,0.8 \mathrm{I} 0)^{* *}$ & $0.632(0.474,0.843)^{* *}$ \\
\hline 6 & $0.687(0.586,0.805)$ & $<0.0001$ & $0.694(0.447,1.077)$ & $0.660(0.53 \mathrm{I}, 0.822)^{* *}$ & $0.705(0.539,0.923)^{*}$ \\
\hline 7 & $0.736(0.632,0.857)$ & $<0.0001$ & $0.740(0.483,1.134)$ & $0.699(0.567,0.862)^{* *}$ & $0.770(0.593,0.998)^{*}$ \\
\hline 8 & $0.772(0.665,0.895)$ & 0.0006 & $0.767(0.504,1.165)$ & $0.736(0.600,0.903)^{* *}$ & $0.806(0.625,1.040)$ \\
\hline 9 & $0.794(0.688,0.917)$ & 0.0017 & $0.777(0.516,1.170)$ & $0.769(0.632,0.935)^{* *}$ & $0.816(0.637,1.046)$ \\
\hline 10 & $0.778(0.676,0.897)$ & 0.0005 & $0.710(0.475,1.061)$ & $0.754(0.622,0.913)^{* *}$ & $0.823(0.643,1.053)$ \\
\hline II & $0.788(0.685,0.906)$ & 0.0008 & 0.745 (0.50I, I. I07) & $0.763(0.632,0.92 \mathrm{I})^{* *}$ & $0.823(0.644, \mathrm{I} .05 \mathrm{I})$ \\
\hline 12 & $0.790(0.688,0.907)$ & 0.0008 & 0.745 (0.50I, I.I07) & $0.765(0.635,0.92 \mathrm{I})^{* *}$ & $0.824(0.646,1.050)$ \\
\hline
\end{tabular}

Notes: Data are presented as reduction in time-to-first exacerbation and $95 \%$ confidence intervals. $* P<0.05 ; * * P<0.005 ; * * * P<0.0001$. 

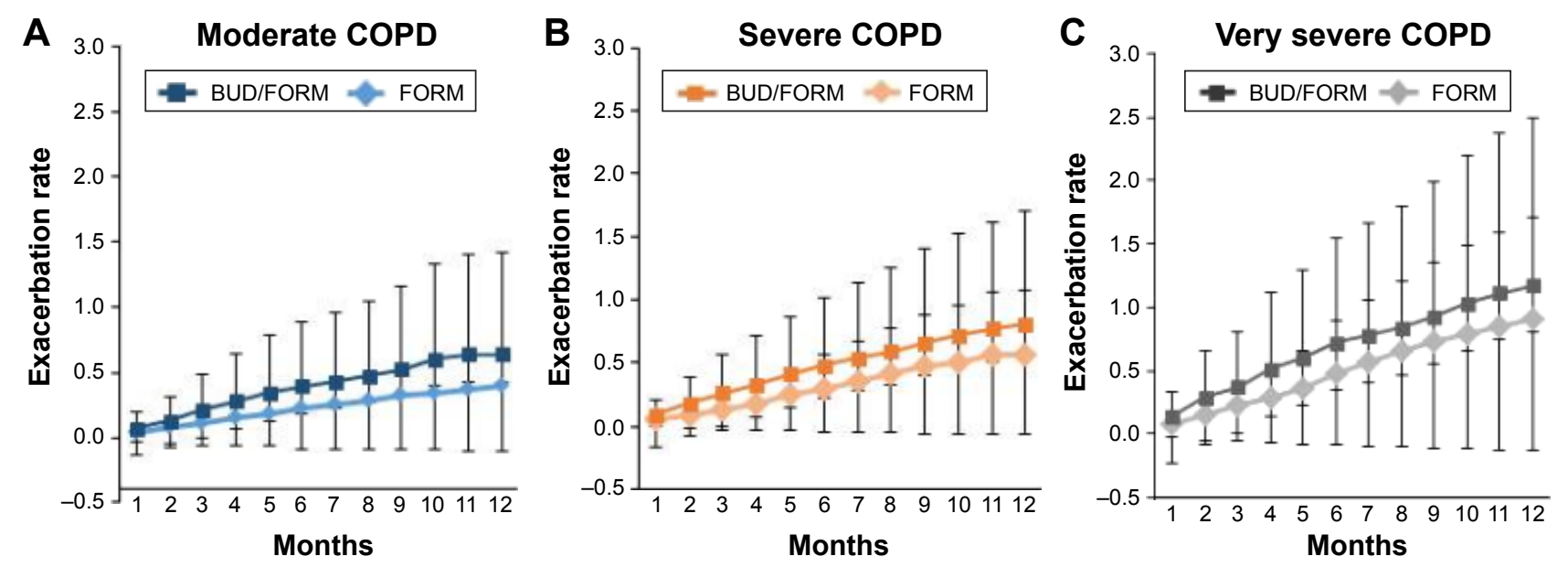

Figure SI Exacerbation rate for budesonide/formoterol and formoterol over time according to COPD disease severity: (A) moderate COPD, (B) severe COPD, and (C) very severe COPD.

Note: Data are presented as $95 \%$ confidence intervals.

Abbreviations: BUD, budesonide; FORM, formoterol.

Table S4 Time-to-discontinuations for budesonide/formoterol versus formoterol in all patients and according to COPD disease severity group

\begin{tabular}{|c|c|c|c|c|c|}
\hline \multirow{3}{*}{$\begin{array}{l}\text { Study } \\
\text { month }\end{array}$} & \multicolumn{5}{|c|}{ Time-to-discontinuations } \\
\hline & \multicolumn{2}{|l|}{ All patients $n=2,345$} & \multicolumn{3}{|l|}{ Disease severity } \\
\hline & & $P$-value & Moderate COPD, n=408 & Severe COPD, n=I,325 & Very severe COPD, $n=612$ \\
\hline I & $0.998(0.519,1.919)$ & 0.9961 & $0.350(0.036,3.369)$ & I. $192(0.494,2.876)$ & $1.000(0.323,3.101)$ \\
\hline 2 & $0.709(0.503,0.999)$ & 0.0494 & $0.791(0.274,2.280)$ & $0.695(0.428,1.130)$ & $0.700(0.406,1.210)$ \\
\hline 3 & $0.65 I(0.500,0.846)$ & 0.0013 & $0.684(0.357,1.312)$ & $0.660(0.454,0.961)^{*}$ & $0.623(0.400,0.972) *$ \\
\hline 4 & $0.665(0.529,0.836)$ & 0.0005 & $0.673(0.383,1.180)$ & $0.692(0.497,0.965)^{*}$ & $0.627(0.427,0.92 I)^{*}$ \\
\hline 5 & $0.724(0.587,0.892)$ & 0.0024 & $0.838(0.5|4| .366)$, & $0.737(0.545,0.997)^{*}$ & $0.655(0.457,0.939)^{*}$ \\
\hline 6 & $0.695(0.57 I, 0.847)$ & 0.0003 & $0.723(0.454,1.153)$ & $0.737(0.556,0.977)^{*}$ & $0.625(0.443,0.882)^{*}$ \\
\hline 7 & $0.723(0.600,0.87 I)$ & 0.0007 & $0.716(0.463,1.110)$ & $0.798(0.611,1.042)$ & $0.631(0.456,0.873)^{*}$ \\
\hline 8 & $0.728(0.609,0.870)$ & 0.0005 & $0.752(0.495,1.142)$ & $0.788(0.608,1.020)$ & $0.639(0.472,0.867)^{* *}$ \\
\hline 9 & $0.735(0.619,0.874)$ & 0.0005 & $0.762(0.506,1.147)$ & $0.802(0.623,1.03 \mathrm{I})$ & $0.637(0.475,0.855)^{* *}$ \\
\hline 10 & $0.750(0.633,0.887)$ & 0.0008 & $0.775(0.521,1.151)$ & $0.834(0.654,1.064)$ & $0.629(0.47 \mathrm{I}, 0.840)^{* *}$ \\
\hline II & $0.761(0.646,0.896)$ & 0.0010 & $0.815(0.553,1.200)$ & $0.822(0.649,1.041)$ & $0.652(0.493,0.863)^{* *}$ \\
\hline 12 & $0.779(0.663,0.915)$ & 0.0023 & $0.850(0.580,1.246)$ & $0.849(0.673$, I.07I) & $0.652(0.496,0.857)^{* *}$ \\
\hline
\end{tabular}

Notes: Data are presented as hazard ratios and $95 \%$ confidence intervals. ${ }^{*} P<0.05 ; * * P<0.005$.

\section{Publish your work in this journal}

The International Journal of COPD is an international, peer-reviewed journal of therapeutics and pharmacology focusing on concise rapid reporting of clinical studies and reviews in COPD. Special focus is given to the pathophysiological processes underlying the disease, intervention programs, patient focused education, and self management protocols

\section{Dovepress}

This journal is indexed on PubMed Central, MedLine and CAS. The manuscript management system is completely online and includes a very quick and fair peer-review system, which is all easy to use. Visit $\mathrm{http} / / / \mathrm{www}$.dovepress.com/testimonials.php to read real quotes from published authors. 